\title{
Determining the Effectiveness of Asphalt Concrete Overlays on Rigid Pavement Using Discrete-Event Simulation
}

\author{
Nathee Athigakunagorn \\ Department of Civil Engineering, Faculty of Engineering at Kamphaeng Saen, Kasetsart University, \\ Nakhon Pathom 73140, Thailand \\ E-mail: nathee.a@ku.th
}

\begin{abstract}
The budget for preserving highway pavement conditions is increasing every year, as well as the impulse to seek transparency of maintenance decisions. This paper presents a new paradigm in applying discrete-event simulation (DES) to capture an indeterministic process of rigid pavement deterioration with an implementation of rehabilitation treatment, namely, asphalt concrete (AC) overlays. This paradigm should facilitate decision makers in establishing the most appropriate maintenance procedure. In this study, the deterioration model was constructed and run over 50 simulated years with various numbers of International Roughness Index (IRI) to determine the rehabilitation cost and average IRI over the analysis period. The result shows that when focusing only on the treatment cost, the best treatment type is Minimal Surface Preparation with 4" AC overlay (MSP). If the treatment performance is considered as the objective for decision making, Crack/Break and Seat section with 8" AC overlay (CB\&S8) provides the best pavement condition. Nevertheless, when both objectives are simultaneously considered, Crack/Break and Seat section with 4" AC overlay (CB\&S4) outperforms the other rehabilitation types, specifically when the treatment is implemented on a good condition pavement with a relatively low IRI. MSP is, however, the most suitable when a pavement is in a less preferable condition with a relatively high IRI.
\end{abstract}

Keywords: Discrete-event simulation, Road maintenance, International roughness index, Asphalt concrete overlays, Infrastructure management.

ENGINEERING JOURNAL Volume 21 Issue 4

Received 15 August 2016

Accepted 9 January 2017

Published 31 July 2017

Online at http://www.engj.org/

DOI:10.4186/ej.2017.21.4.171 


\section{Introduction}

In 2005, Indiana Department of Transportation (INDOT) established the 10-year transportation program called "Major Moves" to set a long-term plan for improving highway infrastructures in the state of Indiana. The mission of this program is to rehabilitate 6,350 miles of highway and 1,070 bridges, which represent nearly $50 \%$ and $20 \%$ of the state's inventory. They also committed to invest over $\$ 11$ billion on new highway construction and preservation between 2006 and 2015. As such, the annual construction budget has increased from $\$ 750$ million to $\$ 1$ billion after the program was launched [1].

With the significant budget and the pursuit of the agency's decision justification and transparency, much research has strived to ascertain an optimal or near-optimal solution for highway infrastructure preservation strategy over the past decades. The major approach is to analyze the Life Cycle Cost (LCC) of the asset with respect to a particular pavement condition threshold [2]. Hence, the purpose of this study is to determine a relationship between the threshold, type of the preservation, and average IRI. As a result, decision makers can foresee the impacts on a selection of preservation method and average post-treatment IRI, as a result of pavement condition threshold identification, especially when the budget is fluctuating.

The focus of this study is on a rigid pavement with five different types of asphalt concrete (AC) overlay rehabilitation. The output, however, is not to identify the type of the rehabilitation that yielded neither the minimum budget nor the minimum average IRI. The study aims to present the trade-off solution between different objectives so that any agency can choose the proper highway rehabilitation strategy to suit their needs and budget. Discrete-Event Simulation (DES) was also implemented to reflect the stochastic nature of the traffic and weather load, and deterioration rate of rigid pavement.

\section{Literature Review}

Numerous researchers and agencies have dedicated their efforts to determine the optimal solution to the asset management problem, specifically in the area of the road pavement maintenance. The insight of this topic has been developed on both the project and network level through assorted papers to reflect those endeavors and awarenesses (see [3] - [7]). Initially, the decision on the pavement maintenance plan was solely depended on a pavement engineer or an asset manager. This would cause problematic inconsistency of the decision because it relied tremendously upon their past experiences or appetences [8]. The previous maintenance data could be another approach to establish a systematic maintenance program. For instance, IRI threshold was acquired from the mean of past IRI values before the treatment, as seen in [8] - [11]. However, it could not clarify if the data was collected based only on engineering aspects or biased by politics, which could preempt the treatment decision. Consequently, this study will treat the threshold as one of an explanatory variable to observe the optimal IRI threshold for each scenario.

The review of the past literature reveals that pavement deterioration is significantly influenced by climatic and traffic load (see [8] - [15]). Nevertheless, the problem would arise when trying to replicate the fluctuation of these two pavement deterioration factors. In fact, there were some attempts from the past studies to address the fortuitousness of pavement maintenance. For example, [16] applied hazard models to predict the probability of pavement service life exceeding pavement condition thresholds. Furthermore, [17] implemented the event tree-based approach to construct the maintenance cost histogram and the probability of a bridge's component failure.

However, those papers described previously are intensively based on mathematical equations to capture the deterioration process. On the other hand, this study takes advantage of randomness to reproduce the uncertainty of deterioration factors, deterioration, and performance increment after pavement maintenance by using DES, which proved useful, especially for construction process analyses, as documented in the past studies ([18] and [19]). Furthermore, this paper integrates and analyzes two conflicting maintenance objectives, minimizing the maintenance cost and minimizing the average IRI, to obtain the best pavement preservation policy.

\section{Performance Model}

To determine the road deterioration, many existing studies have adopted the concept of the pavement performance model. Generally, there are two approaches that are commonly used in establishing a highway performance model: the age-based and condition-based approaches. However, this study applied the 
condition-based approach regarding its capabilities to include attributes that affect highway performance, although significant effort on data collection is needed [20]. The following section will present the relevant concept that is needed for determining the road deterioration.

\subsection{Deterioration Factors and Deterioration Rate}

The deterioration of pavement is contributed to by two dominant aspects, weather and traffic load, which then are utilized as variables to forecast the behavior of highway conditions (see [8], [10], and [14]). The weather and traffic load can be defined as the average annual freeze index in thousands of Celsius-days (ANDX) and average annual truck traffic in millions (AATA), respectively. The highway condition is measured in terms of IRI, as discussed earlier. To calculate the deterioration, this study selected the aggregate performance model that was seen in [16] and [21]-[23]. The benefit of employing the aggregate approach model is that the average of all pavement sections can be analyzed and represented using only one performance model [22]. Hence, for any given ANDX and AADT, IRI (in $\mathrm{m} / \mathrm{km}$ ) in a given year can be computed from the following equation:

$$
I R I=e^{\left(A+\beta_{1} * t * A A T A+\beta_{2} * t * A N D X\right)}
$$

where $\mathrm{t}$ is time since the pavement has been rehabilitated, while $\mathrm{A}$ and $\beta \mathrm{i}$ are the coefficient of the performance model. By differentiating Eq (1) with respect to time $t$, the deterioration rate between any two consecutive years is obtained and shown in Eq (2):

$$
\Delta I R I=\left(\beta_{1} * A A T A+\beta_{2} * A N D X\right) * e^{\left(A+\beta_{1} * t * A A T A+\beta_{2} * t * A N D X\right)}
$$

\subsection{Measurement of Effectiveness (MOE)}

Once the highway has been in service, it then would be gradually deteriorated due to traffic and weather until it reaches a threshold. At this point, the pavement will receive some kinds of treatment, which can be routine maintenance, preventive maintenance, rehabilitation, or reconstruction. After the treatment, the pavement condition will be improved and result in an immediate IRI reduction. This is referred to as performance jump (PJ) or IRI Drop. Normally, this jump can be expressed in a single constant or in a mathematical formula, which has the pre-treatment IRI value as an explanatory variable. This study determines five different types of rehabilitation, which are i) Minimal Surface Preparation with 4" AC overlay (MSP) ii) Minimal Surface Preparation with Saw and Seal of 4" AC overlay (S\&S) iii) Intensive Surface Preparation with 4" AC overlay (ISP) iv) Crack/Break and Seat section with 4" AC overlay (CB\&S4) and v) Crack/Break and Seat section with 8" AC overlay (CB\&S8). Table 1 explains more details of each treatment types. Note that the PJ or IRI Drop equation for each rehabilitation type with some modification will be discussed later in this paper.

Moreover, PJ or IRI Drop is classified as having short-term effectiveness since it measures how much the pavement condition suddenly improves just after one of the treatments from the above-mentioned paragraph is implemented. Long-term effectiveness is the other approach to measure the effectiveness of the treatment, which can be measured in term of average IRI throughout the highway service life or average service life. The average service life is the time elapsed since the last rehabilitation to the next, and can be determined using Eq. (3):

$$
\text { Average Service Life }=\frac{\text { Analysis period }}{\text { Number of rehabilitation during analysis period }}
$$

\subsection{Simulation Model}

Figure 1 represents the pavement deterioration and rehabilitation model. It starts when $t=0$, which can be either a road pavement has been newly constructed or rehabilitated. At this time, the time elapsed since the last maintenance is also 0 (TmLstMtn $=0$ in Fig. 1). Next, the current IRI of the road will be compared with the predetermined IRI threshold. If the present IRI does not exceed the IRI threshold, there is no need for the pavement to undergo any treatment. Hence, the IRI will be increasing with respect to the 
climatic and traffic loads determined from Eq. (2). The new IRI must be computed using Eq. (4) and TmLstMtn will increase by 1 . This process is represented on the left-hand side of Fig. 1. On the other hand, if the current already exceeds the IRI threshold, this means the road will receive a treatment, which will cause IRI Drop and improve the pavement condition. The new IRI is obtained from Eq. (5) and TmLstMtn is reset to 0 . This process is indicated on the right-hand side of Fig. 1, and the entire process will repeat again until it reaches the analysis period.

Table 1. Description of Treatment types. ([22], [23], and [24])

\begin{tabular}{|c|c|}
\hline $\begin{array}{l}\text { Treatment } \\
\text { Type }\end{array}$ & Treatment Description \\
\hline MSP & $\begin{array}{l}\text { Minimal surface preparation performed the following works: potholes filling (limited } \\
\text { patching), crack repair and sealing, joint stabilization, and partial- and full-depth patching, } \\
\text { if warranted. When severe faulting occurred on the section, diamond grinding was } \\
\text { included in the treatment. The } 4 \text { " (102-mm)-thick AC overlay was then placed after the } \\
\text { preparation. }\end{array}$ \\
\hline S\&S & $\begin{array}{l}\text { Minimal surface preparation performed the following works: potholes filling (limited } \\
\text { patching), crack repair and sealing, joint stabilization, and partial- and full-depth patching, } \\
\text { if warranted. When severe faulting occurred on the section, diamond grinding was } \\
\text { included in the treatment. Saw and seal AC overlay was implemented over existing PCC } \\
\text { pavement joints and working cracks. The 4" (102-mm)-thick AC overlay was then placed } \\
\text { after the preparation. }\end{array}$ \\
\hline ISP & $\begin{array}{l}\text { Intensive surface preparation performed the following works: existing partial- and full- } \\
\text { depth patch removal and replacement, implementing additional partial- and full-depth } \\
\text { patching, correcting poor load transfer at joints and/or working cracks by full-depth } \\
\text { patching or retrofitting, retrofitting subsurface edge drainage system, and performing } \\
\text { undersealing, if necessary. The treatment also included diamond grinding and shoulder } \\
\text { rehabilitation. The 4" (102-mm)-thick AC overlay was then placed after the preparation. }\end{array}$ \\
\hline $\mathrm{CB} \& S 4$ & $\begin{array}{l}\text { This treatment used fracturing (cracking and/or breaking) and the seating process on } \\
\text { existing jointed Portland cement concrete pavement (JPCP) to reduce slab size and } \\
\text { minimize or eliminate reflection cracking in the AC overlay. The subsurface edge drainage } \\
\text { system was retrofitted. The } 4 \text { " (102-mm)-thick AC overlay was then placed after the } \\
\text { preparation. }\end{array}$ \\
\hline CB\&S8 & $\begin{array}{l}\text { This treatment used fracturing (cracking and/or breaking) and the seating process on } \\
\text { existing JPCP to reduce slab size and minimize or eliminate reflection cracking in AC } \\
\text { overlay. Subsurface edge drainage system was retrofitted. The } 8 \text { " (203-mm)-thick AC } \\
\text { overlay was then placed after the preparation. }\end{array}$ \\
\hline
\end{tabular}

$$
\begin{gathered}
\text { New IRI }=I R I+\Delta I R I \\
\text { New IRI }=I R I-I R I \_D r o p
\end{gathered}
$$

However, when substituting the analysis from the deterministic to indeterministic approach, it is necessary to employ a simulation program that is capable of replicating the stochastic nature of the highway deterioration process. The program must enable a user to represent the random behavior of the process to any statistical distribution. The EZStrobe [25] simulation program is selected in this study, with the advantage of being equipped with model animation, which is helpful for model verification. The first step to simulate the process using EZStrobe is to construct the Activity Cycle Diagram (ACD). In general, the ACD corresponds to a network of activities and flow of resources in that particular process. This research imitates and discretizes the deterioration and rehabilitation process shown in Fig. 1 to activities, then converts it into ACD for simulation in EZStrobe. The ACD of this process is depicted in Fig. 2. 


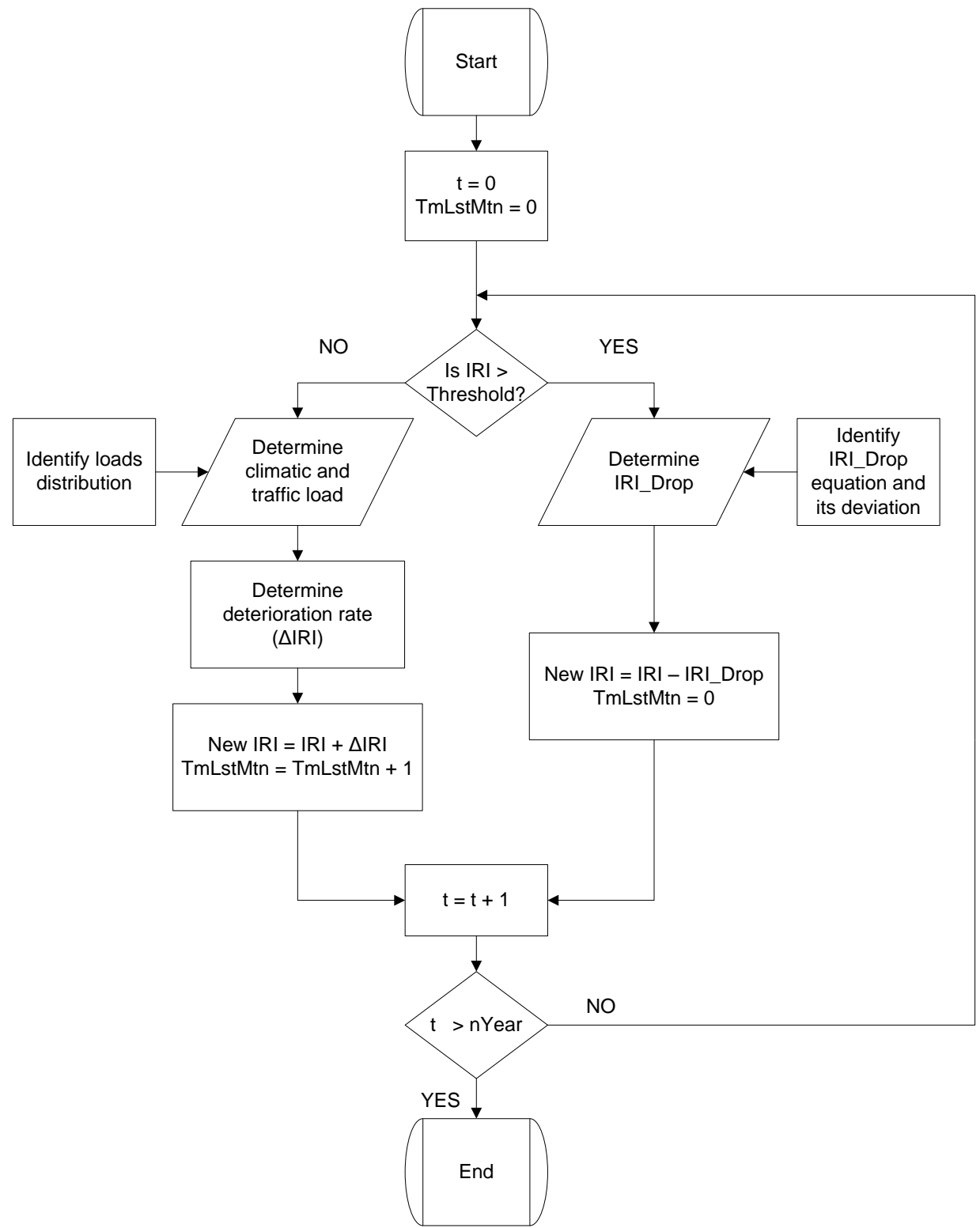

Fig. 1. Pavement deterioration and rehabilitation model.
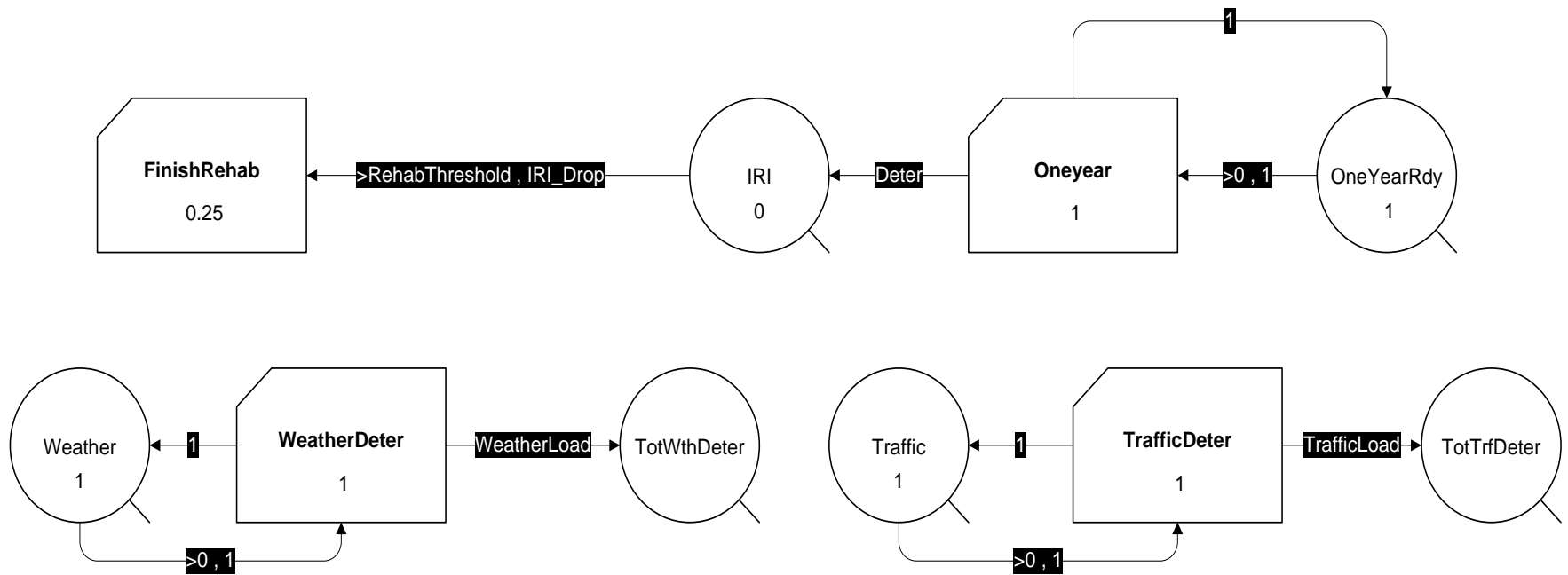

Fig. 2. Activity cycle diagram of pavement deterioration and pavement rehabilitation in EZStrobe. 


\subsubsection{Model description}

The benefit of the ACD is that it intuitively understands what happens in the model if the user knows the role of each element. In Fig. 2, there are a queue (round shape), a condition activity (combi, truncated rectangle), and a draw link connected queue node to and from combi. The first part of a link (for example $>0)$ to a combi specifies the condition to draw resources from the queue with the amount specified in the second part, whereas the link from combi to queue indicates only the amount of resources drawn into the queue.

It is assumed in this model that the deterioration and rehabilitation will happen at the end of each year. Therefore, at the end of each year in simulation time, three activities are bound to finish at the same time. Those activities are WeatherDeter, TrafficDeter, and Oneyear combi. Next, EZStrobe will simulate the weather and traffic load according to a predefined distribution of each activity to calculate the deterioration rate from Eq. (2) for that given year. This is referred to as the WeatherLoad, TrafficLoad, and Deter variable in Fig. 2. As the simulation time proceeds, the number in the IRI queue is piling up (i.e., the length of the IRI queue is getting longer). This is similar to the pavement, which deteriorates if it does not receive any treatment and also is similar to the process described on the left-hand side of Fig. 1. The RehabThreshold variable is the predetermined threshold (in term of IRI) specified by a decision maker to direct EZStrobe to initiate FinishRehab combi instance (i.e., an agency has decided to rehabilitate the highway) if the number accumulating in IRI queue exceeds the RehabThreshold value. Hence, the condition of the pavement will be improved and the IRI value will be reduced by the amount specified from the IRI_Drop variable. This is the same process as depicted on the right-hand side of Fig. 1.

\subsubsection{Model parameters}

To analyze the rehabilitation performance on rigid pavement, some parameters and performance models must be stated. For instance, WeatherDeter and TrafficDeter are assigned as input variables to compute deterioration (Deter in Fig. 2) by using Eq. (2). Furthermore, to take the uncertainty of this process into account, some of the statistical distributions should be implemented. Thus, instead of using a fixed value for AATA, one might assign AATA to be uniformly distributed between the minimum to maximum value. However, it might not be reasonable if we leave all calculations to randomness since it is known that there is a relationship between IRI and the time since the highway was last preserved. This would cause a problem in fitting deterioration rate to any distribution, but the rate does not have independence and identical distribution (IID) characteristics. Yet, we can simulate the stochastic behavior of the process by fitting the deviation of the real data and the trend line (which is depicted by an equation) instead [26].

Table 2 shows i) three coefficients for computing in Eq. (2), namely, $A, \beta_{1}$, and $\beta_{2}$ ii) the equation to evaluate IRI Drop, and iii) the treatment unit cost in 1,000 dollars per lane-km. These parameters and equations were retrieved from the past research ([22] and [23]). The primary data source of this research was retrieved from Specific Pavement Study-6 (SPS-6), which focuses on the rehabilitation effectiveness on JPCPs. Note further that the SPS-6 is the part of the long-term pavement performance (LTPP) program, which gathered pavement data throughout the USA ([22] and [24]).

Additionally, for the PJ equation, IRI Drop is a function of the current pavement IRI, i.e., the current pavement IRI is the explanatory variable of IRI Drop. Moreover, it is assumed that the deviation between values from the equations and real values are uniformly distributed, which is also presented in Table 2. In addition, it is further assumed that the distribution of AATA and AATX for any given year will follow triangular $[3,5,7]$ and triangular $[0.35,0.44,0.52]$, respectively. The predicted traffic growth rate over the simulation period is taken from the previous study and assumed to be $1.55 \%$ [8].

\section{Results}

The model described in the aforementioned section was run for 50 simulated years to determine the effectiveness of rehabilitation types on rigid pavement, both short-term (sudden IRI Drop) and long-term (average IRI over 50 years). The initial IRI was assumed to be zero, which should not alter the result of the short-term performance. For the long-term performance, this could slightly increase the treatment effectiveness but will not impact the comparison between the treatments. Furthermore, the IRI threshold was set from 1.5 to $3.5 \mathrm{~m} / \mathrm{km}$ with the incremental of 0.25 to study the impact of the threshold to total unit cost, average IRI, and average IRI Drop. To avoid fluctuation of the results, the simulation was then run in 
20 replications for each treatment scheme and the seed that controls the random number stream was fixed to ensure that each scheme would experience the same impact of the random number stream. The example of the program output was illustrated in Fig. 3. It was one of 20 replications that presented the IRI of the pavement through the simulation period when the rehabilitation type and IRI threshold were MSP and 1.5 $\mathrm{m} / \mathrm{km}$, respectively.

Table 2. Performance model parameter for each rehabilitation type ([22] and [23]).

\begin{tabular}{|l|l|l|l|l|l|l|l|}
\hline $\begin{array}{l}\text { Treatment } \\
\text { Type }\end{array}$ & $\mathrm{A}$ & $\beta_{1}$ & $\beta 2$ & $\begin{array}{l}\text { Assumed } \\
\text { deviation }\end{array}$ & IRI Drop & $\begin{array}{l}\text { Assumed } \\
\text { deviation }\end{array}$ & $\begin{array}{l}\text { Unit Cost } \\
(\$ 1,000 \text { per } \\
\text { lane-km) }\end{array}$ \\
\hline MSP & -0.025 & 0.015 & 0.053 & $\mathrm{U}[-0.1,0.1]$ & $\mathrm{y}=2.0389 * \ln (\mathrm{x})-0.3273$ & $\mathrm{U}[-0.1,0.05]$ & $\mathrm{U}[350,650]$ \\
\hline S\&S & 0.006 & 0.017 & 0.051 & $\mathrm{U}[-0.1,0.1]$ & $\mathrm{y}=2.1727 * \ln (\mathrm{x})-0.3892$ & $\mathrm{U}[-0.1,0.02]$ & $\mathrm{U}[350,650]$ \\
\hline ISP & 0.031 & 0.032 & 0.022 & $\mathrm{U}[-0.1,0.1]$ & $\mathrm{y}=2.186 * \ln (\mathrm{x})-0.4552$ & $\mathrm{U}[-0.05,0.05]$ & $\mathrm{U}[350,650]$ \\
\hline CB\&S4 & -0.013 & 0.02 & 0.033 & $\mathrm{U}[-0.1,0.1]$ & $\mathrm{y}=1.6637 * \ln (\mathrm{x})-0.067$ & $\mathrm{U}[-0.15,0.05]$ & $\mathrm{U}[350,650]$ \\
\hline CB\&S8 & -0.126 & 0.017 & 0.086 & $\mathrm{U}[-0.1,0.1]$ & $\mathrm{y}=2.6771 * \ln (\mathrm{x})-0.7868$ & $\mathrm{U}[-0.02,0.05]$ & $\mathrm{U}[800,1200]$ \\
\hline
\end{tabular}

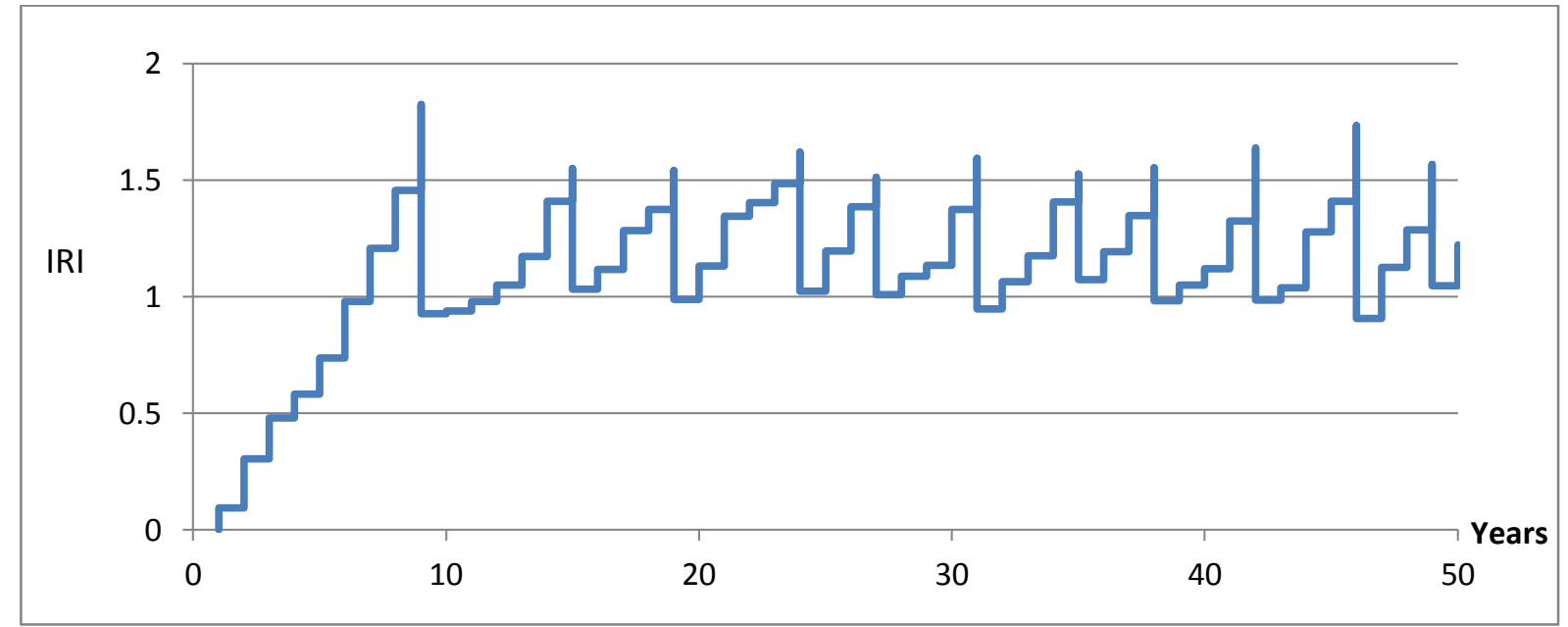

Fig. 3. Performance curve of the pavement from EZStrobe.

\subsection{Condition Performance of Rehabilitation}

Pavement condition after receiving a treatment was investigated for short and long-term effectiveness. Figure 4 plotted the short-term effectiveness of different rehabilitation types using average IRI Drop as an indicator against the IRI threshold. It was found that the treatment that yielded the most average IRI Drop (i.e., the best short-term effectiveness) was CB\&S8; however, there was not a significant difference among these five rehabilitation types when the IRI threshold was $2 \mathrm{~m} / \mathrm{km}$ or lower. In fact, at an IRI threshold equal to $1.5 \mathrm{~m} / \mathrm{km}, \mathrm{CB} \& \mathrm{~S} 8$ produces the worst IRI Drop. It is important to note that this indicator alone is definitely not sufficient to prove the performance of any treatment types over the others because IRI Drop is normally a function of the current pavement IRI. In the other words, the worse pavement condition will result in the higher IRI Drop. 


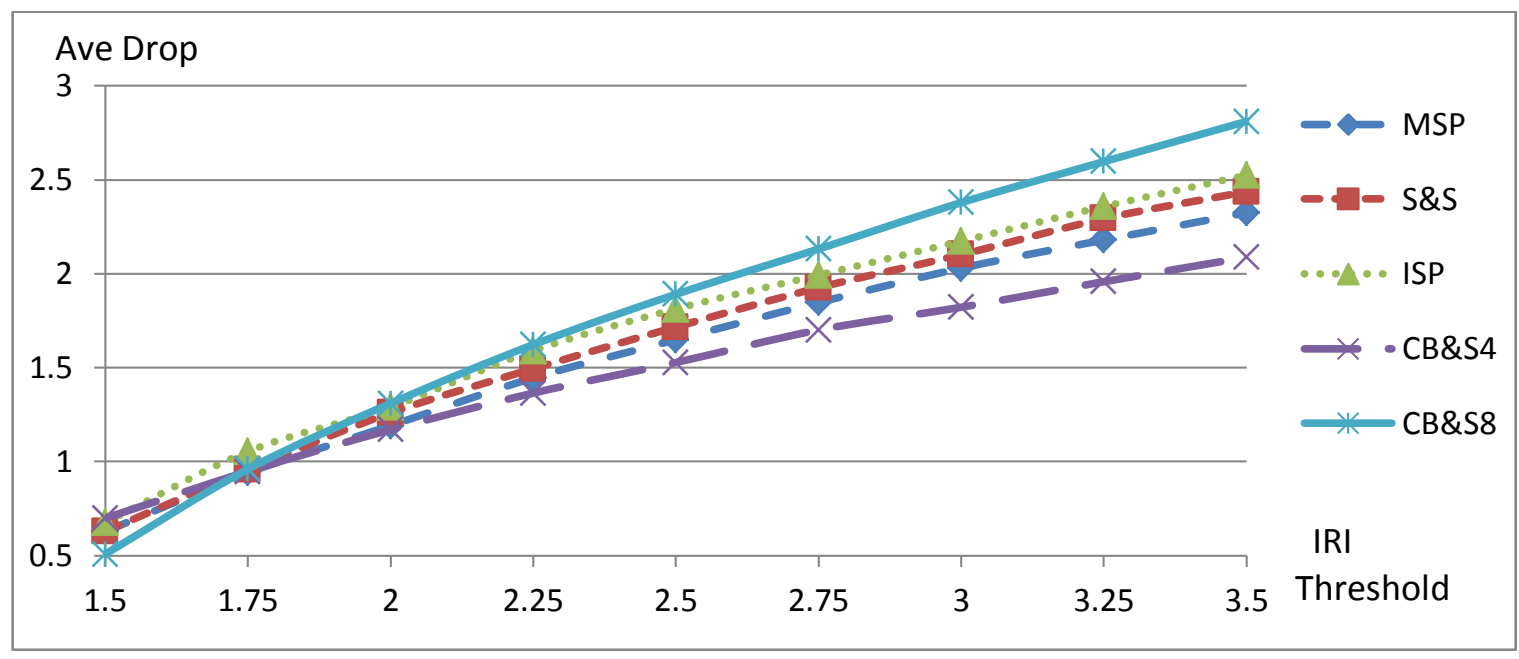

Fig. 4. Short-term performance of the treatment (average IRI drop at various IRI thresholds).

The long-term effectiveness was thus evaluated by observing the average IRI over the 50 -year period and the result was presented in Fig. 5. This study confirmed that the most effective rehabilitation treatment on a rigid pavement was CB\&S8 since it produced the lowest average IRI over the simulation period. Moreover, from both figures, the worst performance rehabilitation was CB\&S4, except when the IRI threshold was below $1.75 \mathrm{~m} / \mathrm{km}$. It is interesting to further investigate that once the pavement performance is excellent (i.e., average IRI is very low), the worst treatment type (CB\&S4) will be selected over the best one (CB\&S8).

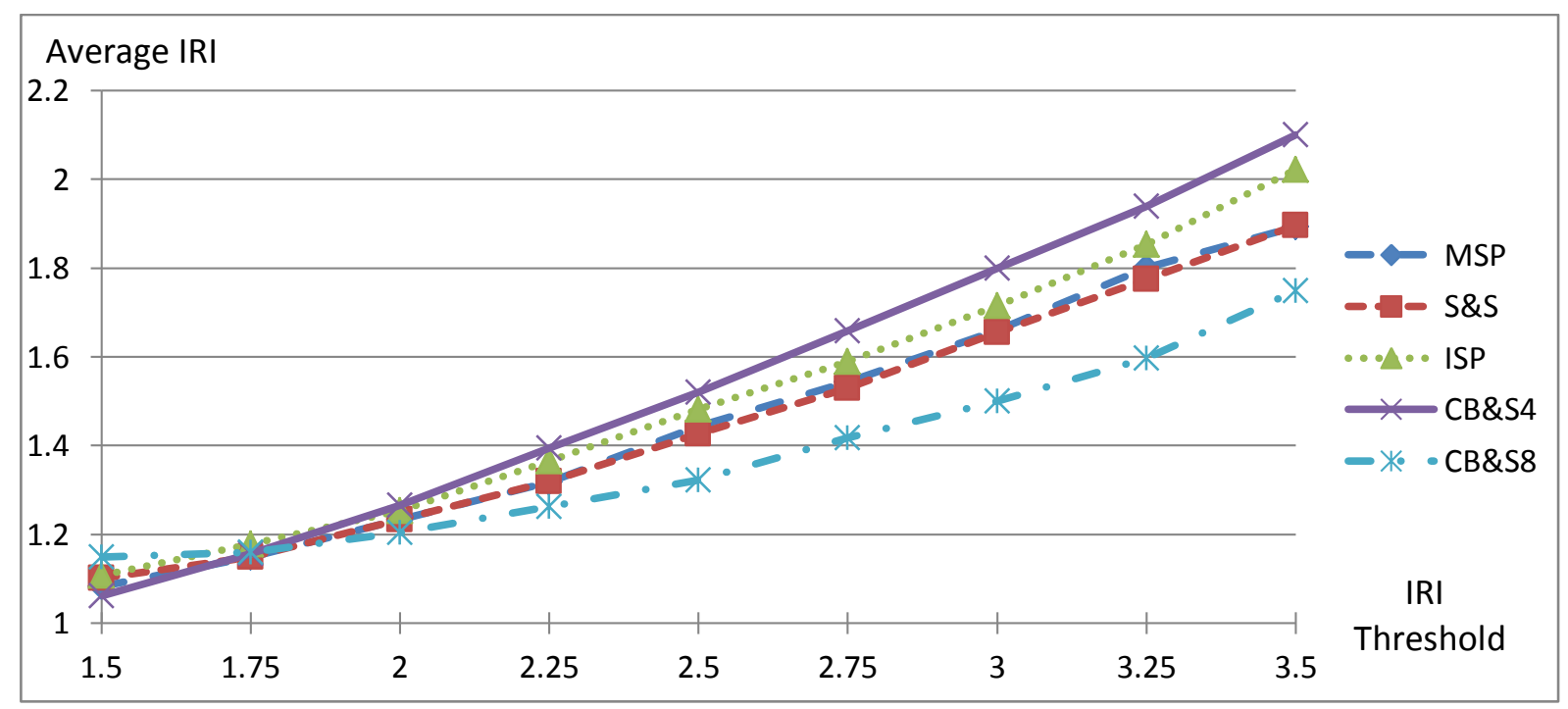

Fig. 5. Long-term performance of the treatment (Average IRI at various IRI thresholds).

\subsection{Cost of Rehabilitation Scheme}

The total lifetime unit costs for each treatment type at different thresholds were collected from the model and demonstrated in Fig. 6. Unlike when pavement condition was considered, the most economical rehabilitation type of rigid pavement was MSP, whereas the most expensive treatment was CB\&S8. The reason was that for CB\&S8, the AC overlay depth was twice as thick as the others. The study then extended to analyze the cost effectiveness (CE) for each treatment by Eq. (6). Note that benefit defined in the study is nonmonetized because it is much easier to evaluate than monetized benefit, and can be defined as an average service life [9]. 


$$
C E=\frac{\text { Effectiveness }}{\text { Cost }}
$$

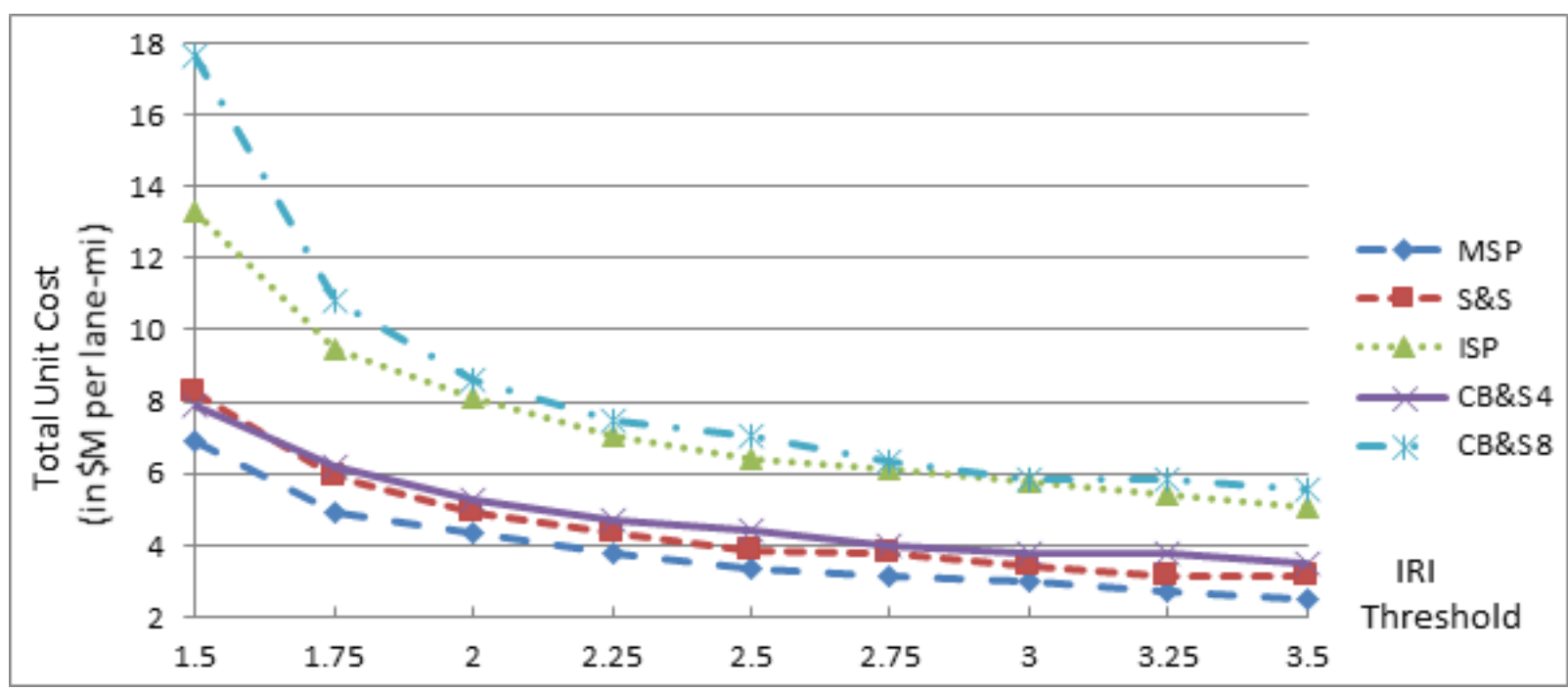

Fig. 6. Total rehabilitation unit cost at various IRI thresholds.

Figure 7 presented the CE for each treatment when the treatment threshold was varied. The results verified the finding discussed earlier that the most effective treatment in term of monetary value was MSP, but the two treatments at the bottom (ISP and CB\&S8) were not notably different, as presented in Fig. 6.

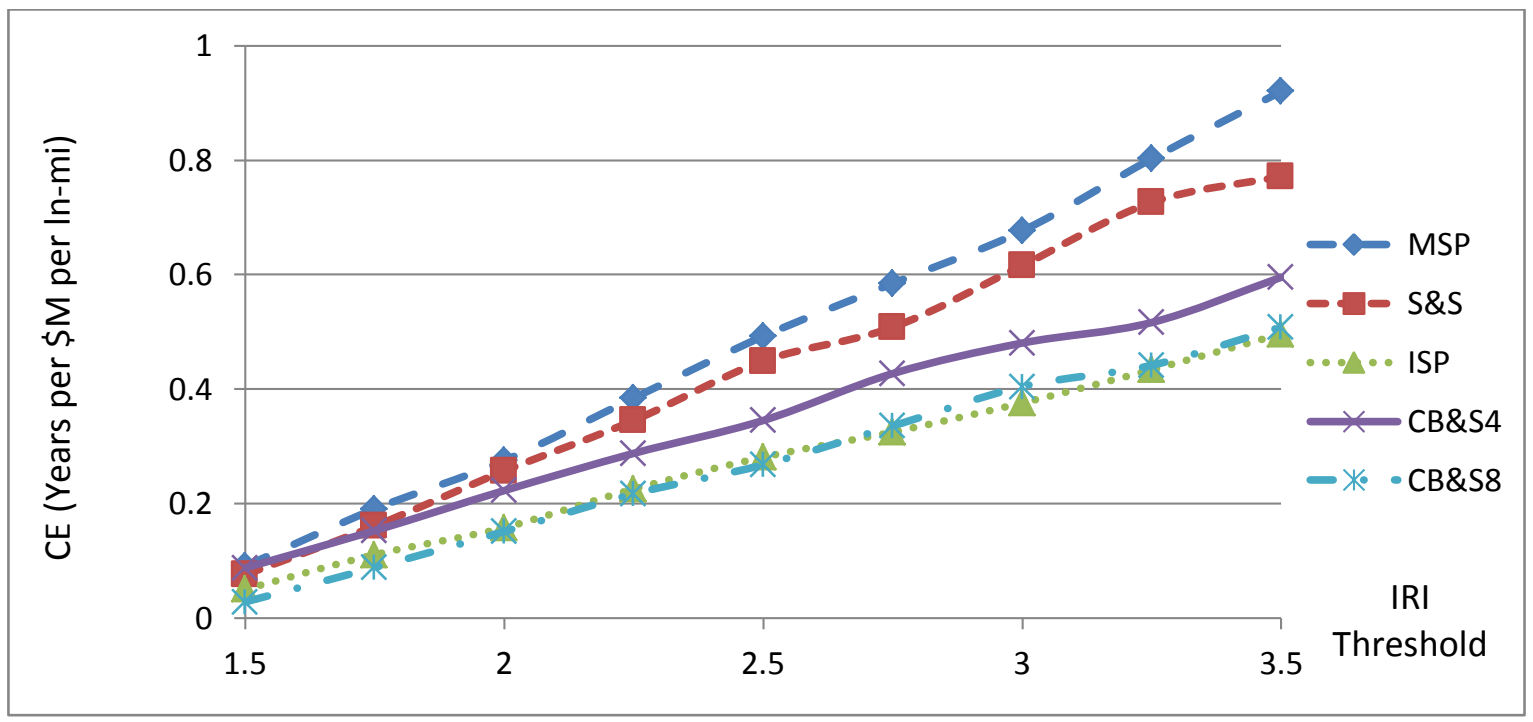

Fig. 7. Cost effectiveness at various IRI thresholds.

\subsection{Multi-objective Optimization and Pareto Front}

From the past two subsections, it is not rational to conclude which treatment is deemed to dominate over the others if one of the aspects, either cost or performance, is considered individually. Thus, they both should be investigated simultaneously to form the multi-objective optimization, and the outcome of the analysis should be a set of non-dominated answers for both aspects [2]. Consequently, it depends on the agency's preference and policy to choose one among those solutions on the Pareto Front depicted in Fig. 8 to perform the maintenance plan. 
It was seen that the utopia point in this study was presented when unit cost and average IRI roughly equaled $\$ 2.53$ million (MSP) and $1.062 \mathrm{~m} / \mathrm{km}(\mathrm{CB} \& \mathrm{~S} 4)$, respectively. The most effective treatment when considering unit cost and average IRI together (i.e., the treatment that has the most points on the Pareto Front) was MSP. However, if excellent pavement condition is required (i.e., the IRI threshold is set to be relatively low), CB\&S4 could be implemented instead of MSP since the Pareto Front was shifted from MSP to the CB\&S4 line, as shown in Fig. 8.

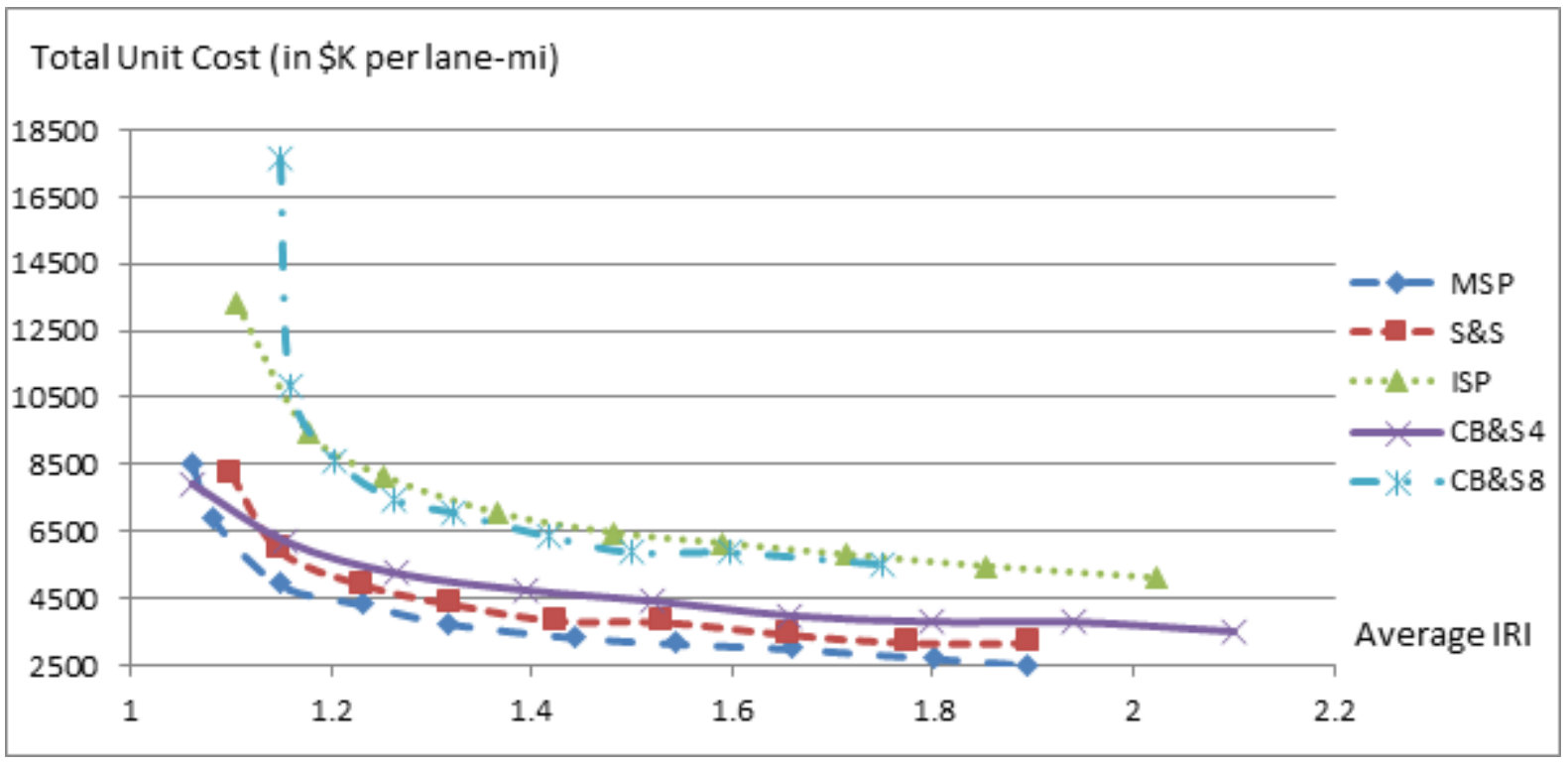

Fig. 8. Trade-off between unit cost and average IRI.

\section{Conclusion and Recommendation}

The new approach to enumerate the effectiveness of five rehabilitation types on a rigid pavement was discussed in this paper. This approach includes the indeterministic part in both existing deterioration and performance formula for the treatment to change the analysis from the deterministic to stochastic method to map the uncertainty of pavement behavior. The deterioration process was discretized and simulated by the EZStrobe simulation program.

The model was run for 50 simulated years with 20 replications. The result revealed that when one discipline was taken into the account, the best performance treatment (the lowest average IRI) was CB\&S8, while the MSP method was the most economical treatment. The Pareto Front was constructed to examine both conflicting aspects simultaneously and establish non-dominated solutions. It was also found that the minimum average IRI over the 20 replications was $1.062 \mathrm{~m} / \mathrm{km}$ when CB\&S4 was the rehabilitation type and the IRI threshold was $1.5 \mathrm{~m} / \mathrm{km}$, whereas the minimum unit cost was $\$ 2.53$ million per lane- $\mathrm{km}$ if MSP was implemented with a $3.5-\mathrm{m} / \mathrm{km}$ IRI threshold.

There are few issues that could enhance and verify the outcomes of the study. First, the analysis should be evaluated at the network level. User equilibrium with some sources of uncertainty should be potentially implemented to initiate traffic load in the network and see the impact of road pavement conditions to the traffic load, and vice versa. Second, this study assumed that IRI is directly correlated to user costs. However, the further study should explicitly investigate the relationship of pavement condition to user costs under the stochastic behavior, which might possibly change the agency's decision on rehabilitation type. This is because road users are nowadays considered to be an agency's customers and their demands for exceptional pavement condition are becoming greater than before.

This study had a fixed period of simulation time. This might be a problem because one treatment activity could happen closer to the end of that period than the others and the study did not consider the benefit beyond that period. The remedy of this issue is to calculate the monetary value of pavement's remaining service life and then subtract it from the total cost. Last, another performance measurement can be included in trade-off analysis so that agencies will have more information and confidence for finalizing their maintenance plans. Furthermore, when performing trade-off analysis, it is not necessary to pair those 
two performance measurements. There are three or more ways trade-off can be analyzed together to determine the most optimum solution for the agency's asset management program. Those additional measurement factors can be average speed, budget, or crash rate.

\section{References}

[1] Indiana Department of Transportation. (2015). Major Moves. [Online]. Available: http://www.in.gov/indot/2407.htm, Accessed on: 19 July 2016.

[2] D. M. Frangapol and M. Liu, "Maintenance and management of civil infrastructure based on condition, safety, optimization, and life-cycle cost," Structure and infrastructure engineering, vol. 3, no. 1, pp. 29-41, Mar. 2007.

[3] N. Athigakunagorn, "Using real options theory to enhance highway asset intervention scheduling," Ph.D. Dissertation, School of Civil Engineering, Purdue Univ., West Lafayette, IN, 2015.

[4] D. M. Frangapol, D. Saydam, and S. Kim, "Maintenance, management, life-cycle design and performance of structures and infrastructures: a brief review," Structure and infrastructure engineering, vol. 8, no. 1, pp. 1-25, Jan. 2012.

[5] T. F. Fwa and K. C. Sinha, and J. D. Riverson, "Highway routine maintenance programming at network level," Journal of Transportation Engineering, vol. 114, no. 8, pp. 539-554, Sep. 1988.

[6] M. B. Khurshid, "A framework for establishing optimal performance thresholds for highway asset interventions," Ph.D. Dissertation, School of Civil Engineering, Purdue Univ., West Lafayette, IN, 2010.

[7] S. Labi, G. Lamptey, and S. H. Kong, "Effectiveness of microsurfacing treatments," Journal of Transportation Engineering, vol. 133, no. 5, pp. 298-307, May 2007.

[8] G. Lamptey, S. Labi, and Z. Li, "Decision support for optimal scheduling of highway pavement preventive maintenance within resurfacing cycle," Decision Support Systems, vol. 46, no. 1, pp. 376-387, Dec. 2008.

[9] M. Irfan, M. Khurshid, and S. Labi, "Determining the service life of thin hot-mix asphalt overlay by means of different performance indicators," Transportation Research Record: Journal of the Transportation Research Board, vol. 2108, pp. 37-45, 2009.

[10] M. B. Khurshid, M. Irfan, S. Labi, and K. C. Sinha, "Cost effectiveness of rigid pavement rehabilitation treatments," in Proceedings of 7th International Conference on Managing Pavement Assets (ICMP A), Calgary, Canada, 2008.

[11] S. Labi, G. Lamptey, S. Konduri, and K. C. Sinha, "Part 1: Pavement management: Analysis of longterm effectiveness of thin hot-mix asphaltic concrete overlay treatments," Transportation Research Record: Journal of the Transportation Research Board, vol. 1940, pp. 1-12, 2005.

[12] A. Ahmed, S. Labi, Z. Li, and T. Shields, "Aggregate and disaggregate statistical evaluation of the performance-based effectiveness of long-term pavement performance specific pavement study-5 (LTPP SPS-5) flexible pavement rehabilitation treatments," Structure and Infrastructure Engineering, vol. 9, no. 2, pp. 172-187, Feb. 2013.

[13] J. Hiller and J. Roesler, "Determination of critical concrete pavement fatigue damage locations using influence lines," Journal of Transportation Engineering, vol. 131, no. 8, pp. 599-607, Aug. 2005.

[14] P. Lu and D. Tolliver, "Pavement pre-and post-treatment performance models using LTPP data," Journal of the Transportation Research Forum, vol. 51, no. 3, pp. 67-81, 2012.

[15] G. P. Ong, T. Nantung, and K. C. Sinha, "Indiana pavement preservation program," Purdue Univ., West Lafayette, IN, FHWA/IN/JTRP-2010/14, 2010.

[16] M Irfan, M. B. Khurshid, S. Labi, and W. Flora, "Evaluating the cost effectiveness of flexible rehabilitation treatments using different performance criteria," Journal of Transportation Engineering, vol. 135, no. 10, pp. 753-763, Mar. 2009.

[17] A. D. Orcesi and D. M. Frangopol, "A stakeholder probability-based optimization approach for costeffective bridge management under financial constraints," Engineering Structures, vol. 33, no. 5, pp. 1439-1449, May 2011.

[18] W. Jiradamkerng, "Evaluation of EZStrobe simulation system as a tool in productivity analysis: A case study—Precast concrete hollow-core slab installation,” Engineering Journal, vol. 17, no. 2, pp. 75-84, 2013. 
[19] W. Jiradamkerng, "Productivity management of road construction in Thailand by EZStrobe simulation system-Case study: $0.15 \mathrm{~m}$. thick subbase course construction,” Engineering Journal, vol. 20, no. 3, pp. 183-195, 2016.

[20] S. Labi, M. M. Rodriguez, and K. C. Sinha, "Assessing preservation needs for a bridge network: A comparison of alternative approaches," Structure and Infrastructure Engineering, vol. 4, no. 3, pp. 221-235, Jun. 2008.

[21] M. Khurshid, M. Irfan, and S. Labi, "Comparison of methods for evaluating pavement interventions: evaluation and case study," Transportation Research Record: Journal of the Transportation Research Board, vol. 2108, pp. 25-36, Nov. 2009.

[22] M. B. Khurshid, M. Irfan, A. Ahmed, and S. Labi, "Multidimensional benefit-cost evaluation of asphaltic concrete overlays of rigid pavement," Structure and Infrastructure Engineering, vol. 10, no. 6, pp. 792-810, Feb. 2013.

[23] S. Labi, "Analyzing the effectiveness of asphaltic concrete overlays as rehabilitation options for rigid pavements," Department of Civil Engineering, Purdue University, 2012.

[24] J. K. Ambroz and M. I. Darter, "Rehabilitation of jointed Portland cement concrete pavements, SPS6-initial evaluation and analysis," FHWA, Washington, DC, Rep. FHWA-RD-01-169, 2005.

[25] J. C. Martinez, "EZStrobe: General-purpose simulation system based on activity cycle diagrams," in Proceedings of the 33rd Conference on Winter Simulation, Washington, D.C., 2001, pp. 1556-1564.

[26] J. C. Martinez, "Methodology for conducting discrete-event simulation studies in construction engineering and management," Journal of Construction Engineering and Management, vol. 136, no. 1, pp. 316, May 2009. 